\title{
A variant of multifocal motor neuropathy with acute, generalised presentation and persistent conduction blocks
}

\author{
J-P Lefaucheur, N A Gregson, I Gray, F von Raison, M Bertocchi, A Créange
}

J Neurol Neurosurg Psychiatry 2003;74:1555-1561

See end of article for authors' affiliations

Correspondence to: Dr J-P Lefaucheur, Service de Physiologie Explorations

Fonctionnelles, Centre Hospitalier Universitaire Henri Mondor, 51 Avenue du Marechal de Lattre de Tassigny, 94010 Creteil, France; jean-pascal.lefaucheur@ hmn.ap-hop-paris.fr

Received 7 October 2002 Revised accepted 5 April 2003
Objective: Multifocal motor neuropathy with persistent conduction blocks is classically described as a chronic neuropathy with progressive onset, and acute forms have not previously been characterised. We report four cases of severe motor impairment with acute and generalised onset and with persistent motor conduction blocks.

Patients and results: An acute tetraparesis with diffuse areflexia but little or no sensory disturbance was the clinical picture. Serial electrophysiological tests showed persistent multifocal motor conduction blocks with absent $\mathrm{F}$ waves in most tested motor nerves. No or minor abnormalities of the sensory nerve action potentials were observed. Cerebrospinal fluid contained normal or mildly increased protein levels $(<1 \mathrm{~g} / \mathrm{l})$ without cells. Campylobacter jejuni serology was negative in three patients and consistent with past infection in one patient. Anti-ganglioside antibodies were positive in three patients. A five day course of intravenous immunoglobulins produced nearly complete symptom resolution in three patients and was ineffective in one patient.

Conclusion: Because of the persistence of multifocal motor conduction blocks for several weeks or months as the isolated electrophysiological feature, these cases could not be consistent with Guillain-Barré syndrome or chronic inflammatory demyelinating polyneuropathy. They suggest an original variant of multifocal motor neuropathy with an acute and generalised initial presentation and persistent motor conduction blocks affecting all four limbs.
M ultifocal motor neuropathy with persistent conduction blocks (MMNCB) is an immune-mediated neuropathy characterised by distal, asymmetric, chronic motor deficits that generally predominate in the upper limbs. ${ }^{1-4}$ Some patients have fasciculations and cramps mimicking anterior horn disease, ${ }^{1}$ but electrophysiological studies show persistent multifocal motor conduction blocks without significant slowing of motor nerve conduction outside the blocks. ${ }^{5}{ }^{6}$

In this study, we describe the cases of four patients who presented with pure motor deficits and persistent multifocal motor conduction blocks without abnormalities outside the blocks. Conduction blocks were defined as an amplitude ratio of responses from proximal to distal stimulation of less than 0.5 , which has been reported to be the most specific and sensitive criterion for defining the conduction blocks in MMNCB.

However, these four cases of MMNCB exhibited two unusual features, which were the acute onset and the generalised involvement of all four limbs. Thus, they suggest that MMNCB could present as an acute and generalised disease. We will discuss the nosological boundaries that separate this original variant of MMNCB from Guillain-Barré syndromes (GBSs), either acute motor axonal neuropathy (AMAN) or acute inflammatory demyelinating neuropathy (AIDP), and from chronic inflammatory demyelinating polyneuropathies (CIDPs) with either an acute onset or a relapsing course.

\section{CASE REPORTS}

\section{Patient one}

A 32 year old woman presented with a history of relapsing weakness in all four limbs, starting in 1985. In 1994, she experienced an episode of diffuse ascending paralysis affecting all four limbs and the face and requiring 24 hours of assisted ventilation. An electrophysiological study dis- closed multiple motor conduction blocks with normal nerve conduction velocities outside the blocks. Cerebrospinal fluid (CSF) examination showed an increased protein concentration $(0.6 \mathrm{mg} / \mathrm{l})$ with no cells. GBS was diagnosed. A 5 day course of intravenous immunoglobulins (IIGs) was given and the patient recovered within a few days. She then experienced relapsing motor deficits in all four limbs, predominating in the distal right upper limb and the left lower limb. Onset was acute, with no precipitating events. At each episode the symptoms improved transiently after intravenous Ig therapy.

At admission, the physical examination showed motor deficits predominating in the right upper limb (extension of the fingers, 3/5) and left lower limb (dorsal flexion of the foot, 4/5). She had difficulty walking on her heels and standing up from the squatting position. All deep tendon reflexes were abolished. There was no evidence of sensory or autonomic system involvement.

An electrophysiological study disclosed motor conduction blocks in both median and ulnar nerves and in the left tibial nerve, as well as prolonged $\mathrm{F}$ wave latencies (table 1 ). Other electrophysiological findings, including sensory nerve conduction parameters, were within the normal range.

The following laboratory tests were negative or normal: blood cell counts, serum electrolyte levels, antinuclear antibodies, rheumatoid factor, and complement fractions. Serological tests were negative for Campylobacter jejuni,

Abbreviations: $M M N C B$, multifocal motor neuropathy with persistent conduction blocks; GBS, Guillain-Barré syndrome; AMAN, acute motor axonal neuropathy; AIDP, acute inflammatory demyelinating neuropathy; CIDP, chronic inflammatory demyelinating polyneuropathy; CSF, cerebrospinal fluid; lg, immunoglobulin; CMAP, compound muscle action potential; HNPP, hereditary neuropathy with susceptibility to pressure palsies; $A M M$ N NCB, acute multifocal motor neuropathy with persistent conduction blocks 


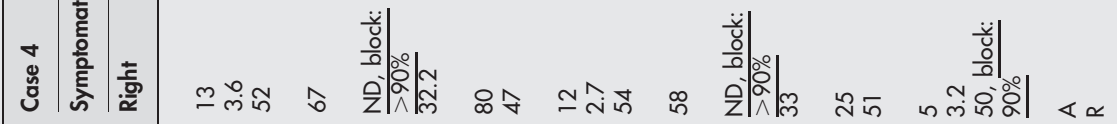

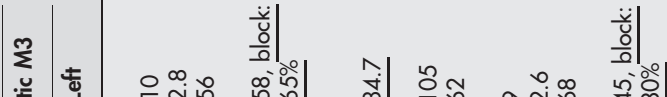

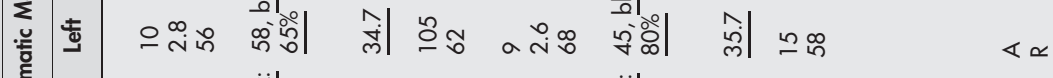
흘

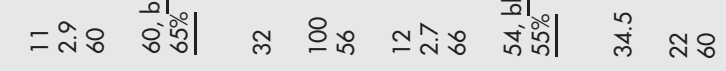

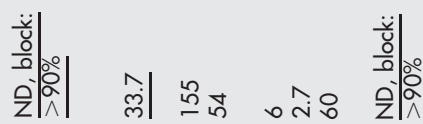
吕|

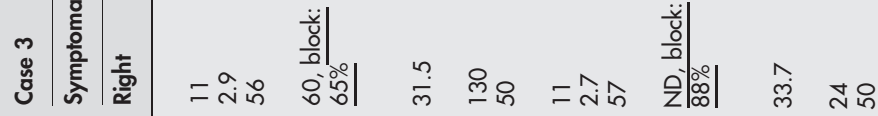

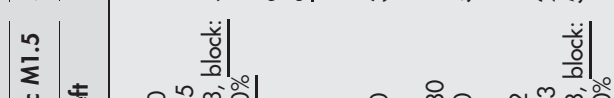

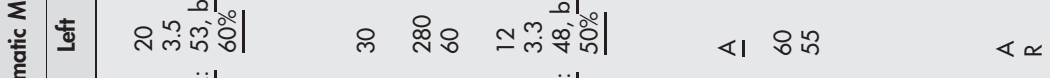

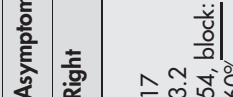
音|

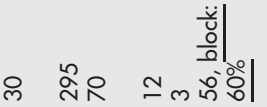
$\varangle 1$ की 8 $\varangle \propto$ $\sum$ क

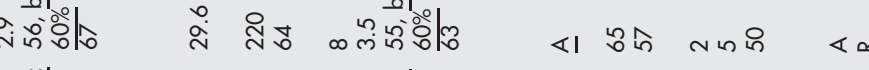
离

응<smiles>[CH]=[CH]</smiles>
ㅎํ잉

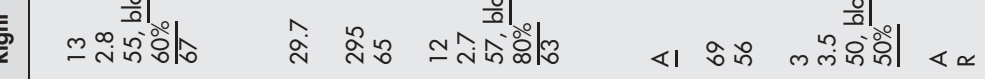

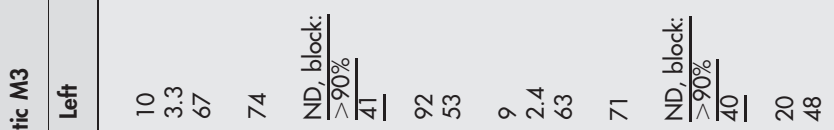

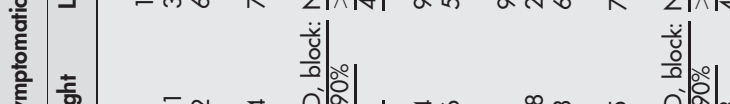

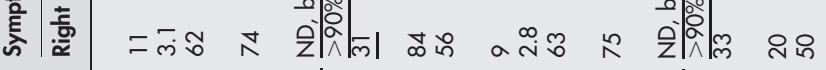

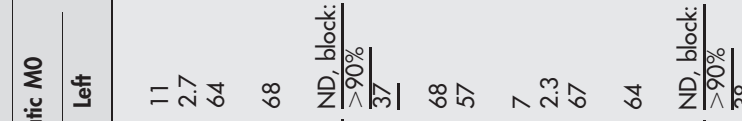
-

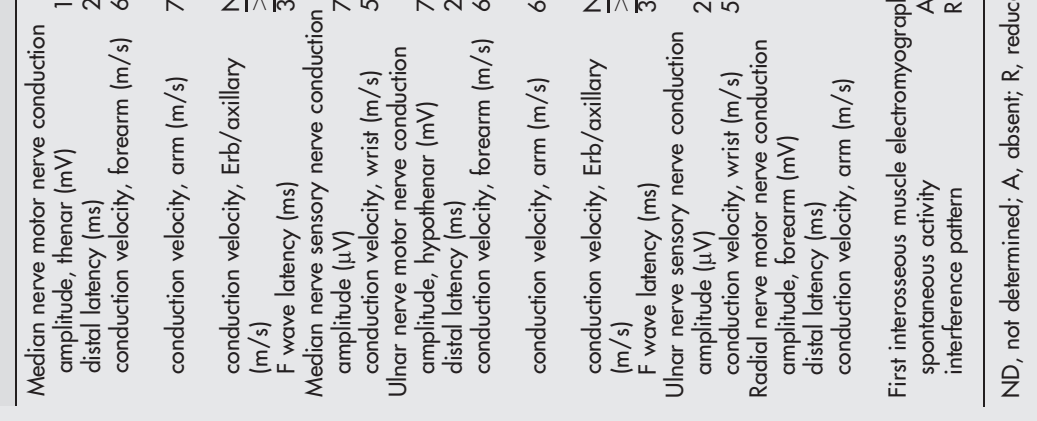




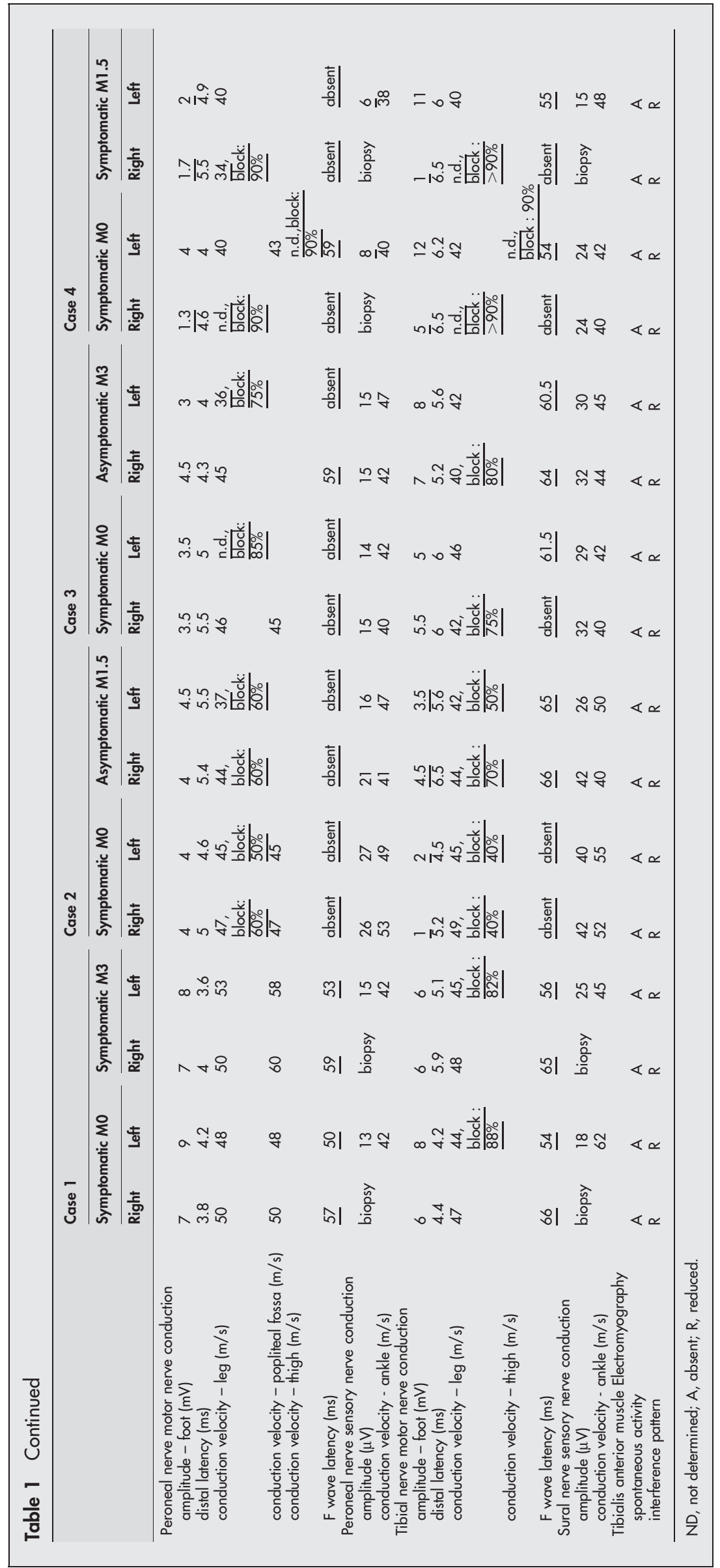


cytomegalovirus, HIV 1 and 2, and hepatitis B and C viruses. There was a polyclonal increase in $\operatorname{IgG}(26.8 \mathrm{~g} / \mathrm{l})$ and $\operatorname{IgM}$ $(3.34 \mathrm{~g} / \mathrm{l})$ levels with a normal IgA level $(2.3 \mathrm{~g} / \mathrm{l})$. Thin layer chromatography detected IgM anti-GMl antibodies.

The motor deficit improved within a few days after a five day course of intravenous Igs $(0.4 \mathrm{~g} / \mathrm{kg} / \mathrm{d})$. A relapse occurred four weeks later with motor deficits at the same sites and with the same intensity as the previous event. An electrophysiological control study was performed three months later and showed persistent multifocal motor conduction blocks (table 1). Following examinations (four and five months after admission) showed the same abnormalities with persistent conduction blocks.

\section{Patient two}

Acute tetraparesis developed within a week in this 29 year old man, who reported a mild episode of sore throat two weeks before motor symptom onset. He had a history of severe obsessive compulsive disorder. At admission three days after symptom onset, he had symmetric lower limb paresis that prevented him from climbing stairs. The weakness worsened rapidly until he was unable to get up from a chair, and then was unable to walk. Physical examination showed symmetrical proximal (2/5) and distal (4/5) motor impairment in the lower limbs, severe proximal $(1 / 5)$ and distal $(2 / 5)$ motor impairment in the upper limbs, and left sided facial paresis. Deep tendon reflexes were abolished. Sensory and autonomic functions were normal.

An electrophysiological study disclosed motor conduction blocks in the median, ulnar, peroneal, and tibial nerves on both sides, with absent $\mathrm{F}$ waves except in the median nerves (table 1). A block was also present in the right radial nerve at the arm. Sensory and other nerve conduction parameters were normal.

CSF examination showed a high protein level $(0.54 \mathrm{mg} / \mathrm{l})$ with a cell count of less than $1 / \mathrm{mm}^{3}$. Most biological findings were normal or negative: blood cell counts, serum electrolyte levels, standard immunological tests, such as tests for antinuclear antibodies and cryoglobulin, and serological tests for cytomegalovirus, Lyme disease, HIV 1 and 2, and hepatitis $\mathrm{B}$ and $\mathrm{C}$ viruses. $\mathrm{C}$ jejuni antibodies were positive in a titre of $1 / 128$, with no increase eight days later. IgM anti-GMl and IgG anti-GM2 antibodies were detected by thin layer chromatography.

A five day course of intravenous $\operatorname{Igs}(0.4 \mathrm{~g} / \mathrm{kg} / \mathrm{d})$ was followed by stabilisation within 24 hours and then recovery to independent walking within three weeks, while conduction blocks persisted. To our knowledge, this patient has not experienced any recurrences.

\section{Patient three}

A 38 year old man was referred to our institution for acute motor impairment in all four limbs, which occurred during a chemotherapy course. He had had diphtheria at 7 years of age. He was taking stavudine, lamivudine, and nelfinavir for HIV 1 infection diagnosed six years earlier. His CD4+ count was $420 / \mathrm{mm}^{3}$ and his viral load was 3470 copies/ml. NonHodgkin's lymphoma developed. During the first chemotherapy course, which combined adriamycin, cyclophosphamide, bleomycin, and methylprednisolone, he experienced an acute episode of tetraparesis that required intensive care unit monitoring. GBS was considered. The neurological manifestations resolved promptly after intravenous Ig therapy. The second course of chemotherapy was followed by diffuse severe motor impairment predominating in the left upper limb (3/5) and right lower limb (2/5). There was diffuse areflexia, but no evidence of sensory, autonomic, or cranial nerve dysfunction.

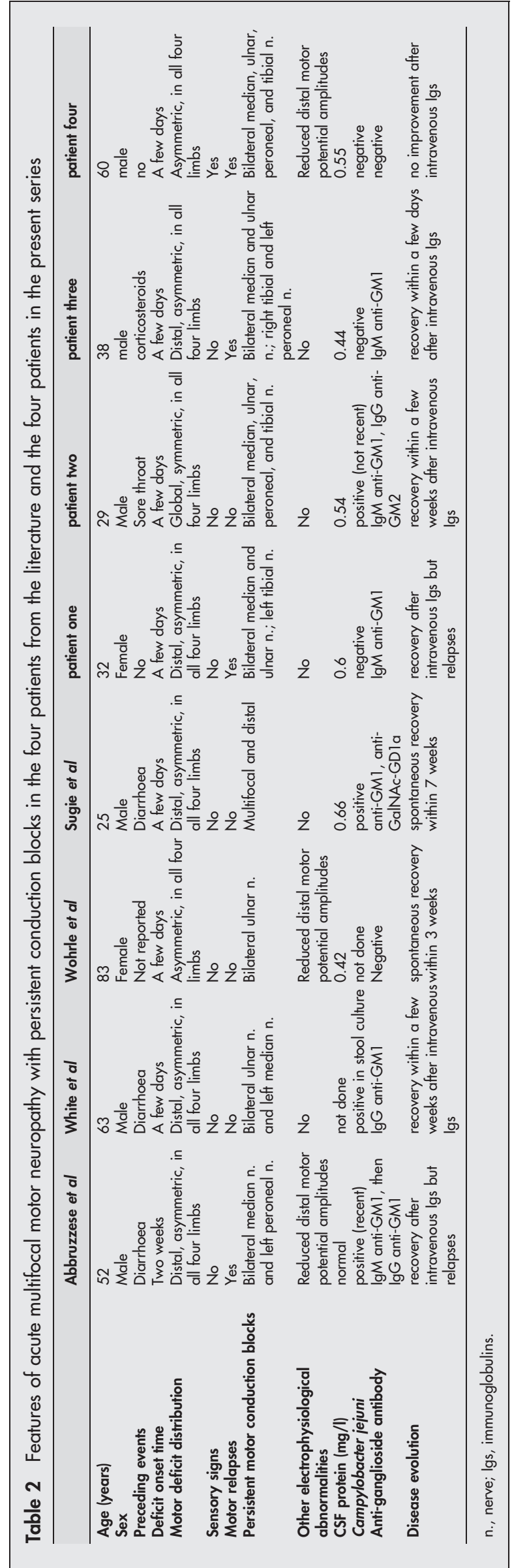


A

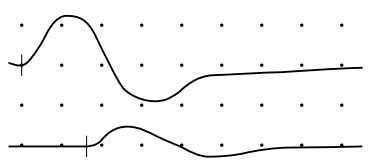

C

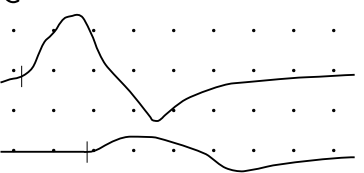

$\mathrm{E}$

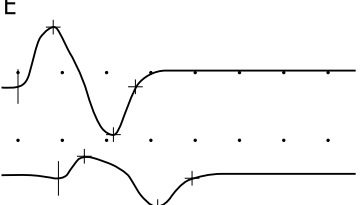

G
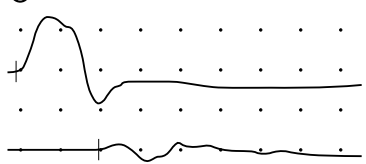

B

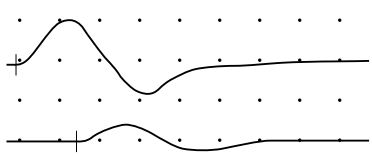

$\mathrm{D}$

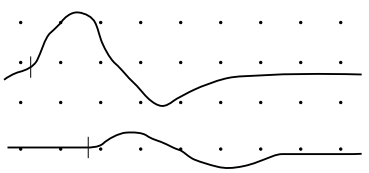

$\mathrm{F}$

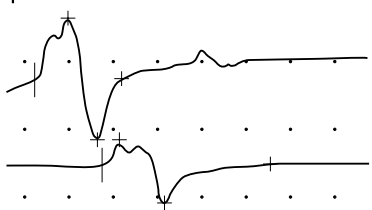

$\mathrm{H}$

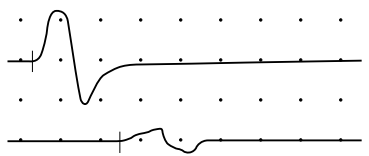

Figure 1 Conduction block. $(A)$ and $(B)$, for the right median nerve, patient three. (C) and (D), for the left ulnar nerve between elbow and Erb point sites of stimulation, patient four. (E) and (F), for the left peroneal nerve, patient two. $(G)$ and $(H)$, for the left tibial nerve between ankle and knee sites of stimulation, patient one. Electrophysiological findings at admission (A, C, E, and $G$ ) and 1.5 or three months later $(B, D, F, H)$ : sweep $5 \mathrm{~ms} /$ division; gain $5 \mathrm{mV} /$ division $(A-D)$ or $2-3 \mathrm{mV} /$ division (E-H).

An electrophysiological study disclosed motor conduction blocks on the right and left median and ulnar nerves, the left peroneal nerve, and the right tibial nerve, with absent $\mathrm{F}$ waves in the lower limbs (table 1). Sensory nerve action potentials and other electrophysiological values in the four limbs were normal.

CSF examination showed a normal protein level (0.44 mg/l) with a cell count of less than $1 / \mathrm{mm}^{3}$. In the blood, the leukocyte count was $2600 / \mathrm{mm}^{3}$ (neutrophils, 1300/ $\mathrm{mm}^{3}$; lymphocytes, $1100 / \mathrm{mm}^{3}$ ), the platelet count was 391000 / $\mathrm{mm}^{3}$, and the haemoglobin level was $10.4 \mathrm{~g} / \mathrm{l}$. Serum electrolyte levels were normal, and the C-reactive protein level was less than $5 \mathrm{mg} / \mathrm{l}$. No antinuclear antibodies were detected. Serological tests were negative for $C$ jejuni and cytomegalovirus. IgM anti-GMl antibodies were found by thin layer chromatography.

The patient recovered completely within two days after initiation of a five day course of intravenous Igs $(0.4 \mathrm{~g} / \mathrm{kg} / \mathrm{d})$. There were no recurrences during the period after the end of chemotherapy during which conduction blocks persisted (according to electrophysiological examinations three, five, and nine months after the initial event).

\section{Patient four}

This 60 year old man was referred for diffuse proximal motor weakness predominating in the right upper limb and both lower limbs. The symptoms had set in within one week. He was taking treatment for diabetes mellitus and for nonHodgkin's lymphoma. He had a history of multiple episodes of motor impairment. The first occurred in 1997 and resolved spontaneously within a few weeks. In 1999, a pure motor deficit occurred in the right lower and upper limbs, associated

with fever and weight loss of $12 \mathrm{~kg}$. Bone marrow examination established the diagnosis of B large cell lymphoma. A biopsy of the right superficial peroneal nerve showed myelinated fibre loss and small perivascular polyclonal inflammatory infiltrates with no visible lymphoma cells. Four courses of chemotherapy were followed by complete remission of the lymphoma and complete resolution of the motor deficit.

The episode that led to referral to our department was characterised by motor impairments in the right upper limb predominating in the radial nerve territory $(1 / 5)$; in the entire right lower limb predominating distally $(2 / 5)$; and in the left lower limb predominating proximally (2/5). Deep tendon reflexes were absent in the lower limbs and right upper limb. Tingling and painful paraesthesia were present in the right lower limb in a radicular distribution.

An electrophysiological study disclosed motor conduction blocks in the median, ulnar, peroneal, and tibial nerves on both sides, with absent $\mathrm{F}$ waves in the right lower limb (table 1). In the left lower limb, proximal magnetic stimulation showed a motor conduction block at the thigh. Another conduction block was present in the right radial nerve at the arm. The amplitude of the distal compound muscle action potentials (CMAPs) was reduced in the right lower limb. In addition, the amplitude of distal sensory nerve action potentials was mildly reduced in the left superficial peroneal nerve, while the right one was impossible to examine because of the previously performed nerve biopsy.

The CSF protein level was elevated $(0.55 \mathrm{mg} / \mathrm{l})$, with a cell count of less than $1 / \mathrm{mm}^{3}$. Blood cell counts were normal and the erythrocyte sedimentation rate was $50 \mathrm{~mm} / \mathrm{h}$. Blood glucose was $6.7 \mathrm{mmol} / \mathrm{l}$. No B cell clonality was found. Bone marrow examination was normal. Findings from a right sural nerve biopsy were similar to those from the first biopsy, with myelinated fibre loss and no lymphocytic infiltrates. No antinuclear antibodies or cryoglobulin were found. Serological tests were negative for $C$ jejuni, cytomegalovirus, HIV 1 and 2, and hepatitis $B$ and $C$ viruses. Thin layer chromatography showed no anti-ganglioside antibodies.

The patient did not recover from motor deficits despite successive courses of intravenous Ig, corticosteroids and rituximab: the motor conduction blocks were persisting.

\section{DISCUSSION}

The presenting clinical picture in all four patients was a pure, severe and diffuse motor impairment with an acute or rapidly progressive onset and areflexia. Only patient four presented with some sensory symptoms (tingling and pain in one limb), but he had no loss of sensation. In addition, three patients had a CSF protein level elevated above $0.45 \mathrm{mg} / \mathrm{l}$. We therefore could suggest that all four patients met the classical diagnostic criteria for GBS. ${ }^{8}$ However, the recurrent episodes of motor impairment observed in three patients raised the possible diagnostic of CIDP, given that relapsing AIDPs can be considered as CIDP variants. ${ }^{9}$

In contrast, the electrophysiological abnormalities presented by the four patients were characterised by multifocal persistent motor conduction blocks, and fulfilled the criteria for MMNCB. ${ }^{5}$ The conduction blocks were found in almost all tested nerves of all four limbs, distally or proximally. Additional conduction blocks may have been present on untested nerves and may have contributed to the generalised and severe presentation of the motor impairment. No motor conduction slowing was noted outside the blocks, but some $\mathrm{F}$ waves were delayed or absent, as usual in MMNCB. The amplitude of the distal CMAPs and the sensory nerve conduction parameters were normal except in patient four. In this patient, the reduction in CMAP amplitudes together with the distribution of the paraesthesia in the right lower 
limb could be related to the existence of a lumbar radiculopathy. In all four patients, the persistence of multifocal conduction blocks without any decrease in distal CMAP amplitude, during more than one month as assessed by serial electrophysiological testing, was not consistent with the figures of "pseudo-conduction blocks" described in vasculitic neuropathy. ${ }^{10}$

Conduction blocks and motor deficits occur in various conditions, and the nosological boundaries separating GBS (in its AIDP or AMAN variants), relapsing CIDP, hereditary neuropathy with susceptibility to pressure palsies (HNPP), and MMNCB deserve discussion.

In favour of the diagnoses of GBS, our cases demonstrated acute pure motor deficit, which could suggest AMAN ${ }^{11-13}$; but they also showed isolated motor conduction blocks, which could be possibly observed in the early phase of AIDP. ${ }^{14-16}$ However, AMAN can be ruled out because this syndrome is electrophysiologically characterised by a marked reduction in distal CMAP amplitude with no conduction block or evidence of segmental demyelination, ${ }^{13}$ and the finding of persistent conduction blocks on serial electrophysiological tests without any additional conduction abnormality is not consistent with long term follow up descriptions of AIDP. ${ }^{17-21}$

Regarding causes of relapsing-remitting neuropathy, CIDP could be invoked, but in CIDP conduction blocks are never observed alone without any other features of demyelination, such as prolonged distal motor latency or slowing of motor nerve conduction in two or more nerves. ${ }^{22-25}$ Relapsingremitting neuropathies have also been described in nonHodgkin's lymphoma. ${ }^{26}$ These cases were histologically characterised by the presence of diffuse lymphoma cell infiltration within the endoneurium. In two successive sensory nerve biopsies, patient four showed some perivascular but no endoneurial infiltration. To be exhaustive, the diagnosis of HNPP should be discussed, because HNPP has been described as a relapsing diffuse motor disorder in rare cases. ${ }^{27}$ However, the conduction blocks in this condition are always located at entrapment sites and are associated with various sensory nerve conduction abnormalities.

Regarding the persistence of pure motor conduction blocks, the four present cases suggest a variant of MMNCB with an acute and generalised initial presentation. Therefore, we suggest that this acute variant of MMNCB (AMMNCB) should be differentiated from GBS, AMAN, and relapsing CIDP.

MMNCB is usually an indolent, chronic, distal, multifocal disease that causes limited disability. ${ }^{3}{ }^{6}$ To our knowledge, only three cases of MMNCB leading to severe quadriplegia have been reported. ${ }^{28-30}$ MMNCB could also include some sensory disorders, in its Lewis-Sumner variant. ${ }^{31}$ This variant may be subacute, but the motor deficit is associated with pain, affecting the upper limbs first and the lower limbs only a few months or years later. Thus, acute and generalised motor impairment is a very unusual presentation of MMNCB. In the literature, we found only five cases compatible with the diagnosis of AMMNCB. ${ }^{32-36}$ Table 2 illustrates the most striking features in these five patients and in the four patients reported in the present study. The conduction blocks recovered within six weeks, in parallel with the improvement in strength in three patients ${ }^{33}{ }^{34}{ }^{36}$ but not in the two other published patients and in the four present cases. An additional case of probable AMMNCB can be found in an older series of "acute relapsing GBS". ${ }^{37}$ In this series of five patients with relapsing diffuse motor deficits, three patients had "normal motor nerve conduction velocities", a feature taken by the authors to distinguish their condition from relapsing CIDP. Interestingly, one of these three patients "had conduction blocks in several nerves three years after a second acute episode of GBS", which was reported as a "purely motor syndrome" with onset within one week after an episode of diarrhoea.

The pathophysiological mechanisms of AMMNCB probably overlap those of chronic MMNCB. MMNCB is usually associated with anti-GMI antibodies and may be related to $C$ jejuni infection. ${ }^{238}$ The same is true of AMAN. ${ }^{39}$ In the present series of AMMNCB, the serological profile of one patient was consistent with past colonisation with $C$ jejuni, and anti-GM1 and anti-GM2 antibodies were found in three patients. In the five previous cases of probable AMMNCB found in the literature, $C$ jejuni enteritis was present in four patients, and anti-ganglioside antibodies in three patients.

Regarding the treatment, a relapsing course and a good response to repeated intravenous Ig administration are classically described in MMNCB. ${ }^{40}$ In contrast, abrupt motor deficit may result from the use of corticosteroids. ${ }^{42}$ In the present series of $\mathrm{AMMNCB}$, three patients recovered following intravenous Igs, as did three patients in the literature, whereas corticosteroids seemed to have caused the relapses of motor deficit in our patient three. Thus the usual, chronic form of MMNCB and AMMNCB have similar profiles of response to treatment.

To conclude, AMMNCB may be considered a variant of MMNCB that should be differentiated from GBS, AMAN, relapsing GBS, and CIDP. Typical features of AMMNCB may include diffuse, severe motor impairment with an acute or rapidly progressive onset, usually affecting all four limbs, often in an asymmetric distribution, and with electrophysiological evidence of pure, generalised motor conduction blocks without any other motor or sensory nerve conduction abnormalities. Additional features may include a relapsing course, a slightly increased CSF protein concentration, various anti-ganglioside antibodies, and a response to intravenous Ig therapy, while motor conduction blocks persist.

\section{Authors' affiliations}

J-P Lefaucheur, Service de Physiologie - Explorations Fonctionnelles, CHU Henri Mondor, Assistance Publique-Hôpitaux de Paris, Créteil, France

N A Gregson, I Gray, Department of Neuroimmunology, Guy's, King's and St Thomas' School of Medicine, London, UK

F von Raison, A Créange, Service de Neurologie, CHU Henri Mondor, Assistance Publique-Hôpitaux de Paris, Créteil, France

Marc Bertocchi, Service d'Immunologie Clinique, CHU Henri Mondor, Assistance Publique-Hôpitaux de Paris, Créteil, France

This work was first presented at the annual meeting of the American Academy of Neurology, Philadelphia, May 2001.

\section{REFERENCES}

1 Parry GJ, Clarke S. Multifocal acquired demyelinating neuropathy masquerading as motor neuron disease. Muscle Nerve 1988;11:103-7.

2 Pestronk A, Cornblath DR, llyas AA, et al. A treatable multifocal motor neuropathy with antibodies to GM1 ganglioside. Ann Neurol 1988;24:73-8.

3 Parry GJ. AAEM Case report \#30: multifocal motor neuropathy. Muscle Nerve 1996; 19:269-76.

4 Pestronk A. Multifocal motor neuropathy: diagnosis and treatment. Neurology 1998;51(suppl):S22-4.

5 Jaspert A, Claus D, Grehl H, et al. Multifocal motor neuropathy: clinical and electrophysiological findings. J Neurol 1996;243:684-92.

6 Taylor BV, Wright RA, Harper CM, et al. Natural history of 46 patients with multifocal motor neuropathy with conduction block. Muscle Nerve 2000;23:900-8.

7 Pfeiffer G, Wicklein EM, Wittig K. Sensitivity and specificity of different conduction block criteria. Clin Neurophysio 2000;111:1388-94.

8 Asbury AK, Cornblath DR. Assessment of current diagnostic criteria for Guillain-Barré syndrome. Ann Neurol 1990;27(suppl):S21-4.

9 Gorson KC, Allam G, Ropper AH. Chronic inflammatory demyelinating polyneuropathy: clinical features and response to treatment in 67 consecutive patients with and without a monoclonal gammopathy. Neurology 1997;48:321-8.

10 Ropert A, Metral S. Conduction block in neuropathies with necrotizing vasculitis. Muscle Nerve 1990;13:102-5. 
11 Ho TW Mishu B Li CY et al Guillain-Barré syndrome in northern China Relationship to Campylobacter jejuni infection and anti-glycolipid antibodies. Brain 1995; 118:597-605.

12 Hafer-Macko C, Hsieh ST, Li CY, et al. Acute motor axonal neuropathy: an antibody-mediated attack on axolemma. Ann Neurol 1996:40:635-44.

13 McKhann GM, Cornblath DR, Griffin JW, et al. Acute motor axonal neuropathy: a frequent cause of acute flaccid paralysis in China. Ann Neurol 1993;33:333-42.

14 Brown WF, Feasby TE. Conduction block and denervation in Guillain-Barré polyneuropathy. Brain 1984; 107:219-39.

15 Brown WF, Snow R. Patterns and severity of conduction abnormalities in Guillain-Barré syndrome. J Neurol Neurosurg Psychiatry 1991;54:768-74.

16 Albers JW, Donofrio PD, McGonagle TK. Sequential electrodiagnostic abnormalities in acute inflammatory demyelinating polyradiculoneuropathy. Muscle Nerve 1985;6:504-9.

17 McLeod JG. Electrophysiological studies in the Guillain-Barré syndrome. Ann Neurol 1981;9(suppl):20-7.

18 Van Der Méché FGA, Meulstee J, Vermeulen M, et al. Patterns of conduction failure in the Guillain-Barré syndrome. Brain 1988:111:405-16.

19 Cornblath DR, Mellits ED, Griffin JW, et al. Motor conduction studies in Guillain-Barré syndrome: description and prognostic value. Ann Neurol 1988;23:354-9.

20 Ropper AH, Wijdicks EF, Shahani BT. Electrodiagnostic abnormalities in 113 consecutive patients with Guillain-Barre syndrome. Arch Neurol 1990;47:881-7.

21 Gordon PH, Wilbourn AJ. Early electrodiagnostic findings in Guillain-Barré syndrome. Arch Neurol 2001;58:913-17.

22 Albers JW, Kelly Jr JJ. Acquired inflammatory demyelinating polyneuropathies: clinical and electrodiagnostic features. Muscle Nerve 1989; 12:435-51.

23 Research criteria for diagnosis of chronic inflammatory demyelinating polyneuropathy (CIDP). Report from an ad hoc subcommittee of the American Academy of Neurology AIDS Task Force. Neurology 1991;41:617-18.

24 Bromberg MB. Comparison of electrodiagnostic criteria for primary demyelination in chronic polyneuropathy. Muscle Nerve 1991;14:968-76.

25 Cornblath DR, Chaudhry V, Griffin JW. Treatment of chronic inflammatory demyelinating polyneuropathy with intravenous immunoglobulin. Ann Neurol 1991;30:104-6.

26 Gherardi R, Gaulard P, Prost C, et al. T-cell lymphoma revealed by a peripheral neuropathy. A report of two cases with an immunohistologic study on lymph node and nerve biopsies. Cancer 1986;58:2710-16.
27 Le Forestier N, LeGuern E, Coullin P, et al. Recurrent polyradiculoneuropathy with the 17p1 1.2 deletion. Muscle Nerve 1997;20:1 184-6.

28 Roth G, Rohr J, Magistris MR, et al. Motor neuropathy with proximal multifocal persistent conduction block, fasciculations and myokymia. Evolution to tetraplegia. Eur Neurol 1986;25:416-23.

29 Van den Bergh P, Logigian EL, Kelly Jr JJ. Motor neuropathy with multifocal conduction blocks. Muscle Nerve 1989;12:26-31.

30 Beydoun SR, Rison RA, Commins D. Secondary amyloidosis as a life-ending event in multifocal motor neuropathy. Muscle Nerve 2001;24:1396-402.

31 Lewis RA, Sumner AJ, Brown MJ, et al. Multifocal demyelinating neuropathy with persistent conduction block. Neurology 1982;32:958-4.

32 Abbruzzese M, Reni L, Schenone A, et al. Multifocal motor neuropathy with conduction block after Campylobacter jejuni enteritis. Neurology 1996;48:544.

33 White JR, Sachs GM, Gilchrist JM. Multifocal motor neuropathy with conduction block after Campylobacter jejuni. Neurology 1996:46:562-3.

34 Wohrle JC, Amoiridis G, Heye N, et al. Acute multifocal motor neuropathy with early spontaneous recovery: a distinct syndrome from Guillain-Barré syndrome? Electromyogr Clin Neurophysiol 1996;36:37-41.

35 Sugie K, Murata K, lkoma K, et al. A case of acute multifocal motor neuropathy with conduction block after Campylobacter jejuni enteritis. Rinsho Shinkeigaku 1998;38:42-5.

36 Corcia P, Beaume A, Guennoc AM, et al. Neuropathie motrice aiguë démyélinisante secondaire à une gastro-entérite : une forme atypique de syndrome de Guillain-Barré ? Rev Neurol (Paris) 1999;155:596-7.

37 Wijdicks EF, Ropper AH. Acute relapsing Guillain-Barré syndrome after long asymptomatic intervals. Arch Neurol 1990;47:82-4.

38 Yuki N. Anti-ganglioside antibody and neuropathy: review of our research. J Peripher Nerv Syst 1998:3:3-18.

39 Hadden RD, Gregson NA. Guillain-Barré syndrome and Campylobacter jejuni infection. Symp Ser Soc Appl Microbiol 2001;30(suppl):S145-54.

40 Chaudry V, Corse AM, Cornblath DR, et al. Multifocal motor neuropathy: response to human immune globulin. Ann Neurol 1993;33:237-42.

41 Nobile-Orazio E, Meucci N, Barbieri S, et al. High-dose intravenous immunoglobulin therapy in multifocal motor neuropathy. Neurology 1993:43:537-44.

42 Donaghy M, Mills KR, Boniface SJ, et al. Pure motor demyelinating neuropathy: deterioration after steroid treatment and improvement with intravenous immunoglobulin. J Neurol Neurosurg Psychiatry 1994:57:778-83.

\section{$\mathrm{ECHO}$}

\section{Eye traits identify coma types}

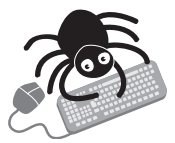

Please visit the Journal of Neurology, Neurosurgery, and Psychiatry website [www.jnnp. com] for a link to the full text of this article. $\mathrm{n}$ future, comatose patients - the bulk of those seen in emergency departments-could

have the cause of their coma identified by simple eye tests. A prospective probabilistic study has for the first time confirmed loss of light reflex and unequal pupil size as important diagnostic criteria.

These two criteria independently predicted coma with a structural cause in multivariate analysis corrected for age, sex, and level of consciousness (odds ratio 11.02 (95\% confidence interval 3.9 to 30.9) for loss of light reflex and 7.5 (1.4 to 39.4) for unequal pupil size). The likelihood ratio of a positive result in structurally caused coma was 9.0 for unequal pupil size and 3.59 for loss of light reflex. The results were based on tests in 115 patients, 113 of whom had a final diagnosis of structurally $(40 \%)$ or metabolically $(60 \%)$ caused coma. The precise cause was also ascertained. The results for the cohort matched probability estimates quoted in textbooks but not rigorously evaluated until now.

Comatose patients aged $\geqslant 15$ years seen in the emergency department of a community teaching hospital during a year were recruited consecutively. All had initial eye tests, full physical and neurological examinations, basic biochemical tests, and imaging tests, if clinically necessary. They were followed up as inpatients, and their medical records were reviewed after a year. One clinical researcher, two if there was disagreement, reviewed the likely cause of the coma.

Usefulness of these two criteria in differential diagnosis of coma has been poorly described before. Differential diagnosis is usually based on clinical experience.

A Postgraduate Medical Journal 2003;79:49-51. 